\title{
DANCING ACROSS GENDER BOUNDARIES. AN EXPLORATION ON THE PROCESS OF GENDER IDENTITY CONSTRUCTION THROUGH THE INDIAN CLASSICAL DANCE BHARATANATYAM
}

\author{
Sara AzZARelli \\ Choreomundus Master Programme - International Master in Dance Knowledge, Practice and Heritage \\ 06034, Foligno, Via Verona 48, Italy \\ E-mail: sara.azzarelli7@gmail.com
}

\begin{abstract}
Gender dynamics play an essential role within the Indian classic dance Bharatanatyam. In the narrative component of this choreutic form, the Abhinaya, dancers are demanded to enact both male and female roles, using codified series of bodily attitudes and gestures. These acts of impersonation can sometimes become a mean for them to go beyond their "actual" gender and explore different attitudes and feelings. My research investigates what this process could mean for those social actors who place themselves out of the mainstream dichotomy male man/female woman. Assuming the Constructivist and anti-Essentialist perspective, according to which gender and sexuality are not naturally fixed qualities, but changeable and unstable cultural constructs, I attempt to explore the place Abhinaya could have in this process of self-shaping for homosexual, bisexual and transgender dancers. This essay, basing on the ethnographic fieldwork I conducted during summer 2013 in Chennai (Tamil Nadu, India) with a LGBT group of dancers, explores individual modalities of crossing gender boundaries through Bharatanatyam.
\end{abstract}

Keywords: Bharatanatyam, Abhinaya, gender identity, LGBT, queerness, Tamil Nadu

\section{INTRODUCTION}

What I consider to be one of the most interesting elements characterizing the Indian classical dance style Bharatanatyam ${ }^{l}$, is the modality in which dancers are demanded and at the same time allowed to move across gender boundaries. In the narrative component

${ }^{1}$ Although the assumed ancient origins Bharatanatyam, this choreutic form is mostly the result of a recent codification process made by professional Indian dancers during the first half of the $20^{\text {th }}$ century, Bharatanatyam's more ancient predecessor, a choreutic form called sadir, which used to be performed by the devadasi (temple's dancers at the service of the deities), was declared immoral and stigmatized during British colonialism, since it was associated with the non-domestic life style of devadasi, largely considered as prostitution (O'SHEA 2002: 4.). Bharatanatyam comes from Indian dancers' need to re-establish sadir's dignity, dissociating it from the ritual dancers system and connecting it to the ancient period the Orientalists considered the cultural culmination of Indian civilization: the age of Veda and big drama treatises. 
of this choreutic form, the Abhinaya, ${ }^{2}$ they use facial expression and bodily attitudes to tell episodes from the big corpus of Hindu epic and mythology, becoming any character of the story: a king, a god, a princess, a lover, a demon. During my four years of training in Bharatanatyam, I experienced how this process of impersonation should go beyond gestures, beyond physical technique: the transformation should be deeper than merely creating a physical image. ${ }^{3}$ As the Natyasastra, popular ancient treatise on Indian dramaturgy specifies, the aim of a Bharatanatyam dancer is to express feeling moods or bhavas, situations and acts in order to evoke in the spectator the appropriate emotive responses, the $\operatorname{rasas}^{4,5}$. The exploration of gender nuances would therefore need to be real: for transmitting an emotional state in the way a certain character would do, the dancer should deeply experience what that character would feel. Thus, these acts of impersonation can sometimes become a mean for dancers to explore different bodily attitudes and feelings, to express emotions in different ways from what they are socially expected to do, to dance across culturally fixed boundaries of gender and sexuality. This essay investigates what this process could mean for those social actors who place themselves out of the mainstream dichotomy male man/female woman, those social actors who constantly cross those cultural borders also in everyday life.

In the house of Anthropology and Feminist Studies, gender and sexuality are generally considered not as naturally fixed qualities, but as multiple, changeable, unstable cultural constructs. Assuming therefore a Constructivist and anti-Essentialist perspective, according to which 'the process of gendering sexed bodies is a constant shifting, reworking and reauthorizing of one's identity undertaken against or with local, state and transnational discourses ${ }^{,}{ }^{6}$ I will attempt to explore the place Abhinaya could have in this process of continuous redefinition. This exploration will base on the ethnographic fieldwork I conducted in the summer of 2013 in Chennai (Tamil Nadu, India), during which I had the opportunity to collaborate with homosexual, bisexual and transgender Bharatanatyam dancers. Emphasizing the diversity of their experiences, their individual meanings, this essay is an attempt at exploring how Bharatanatyam Abhinaya could become a cultural space where social actors can continuously modify, re-iterate, re-confirm and even reinvent themselves and their own worlds.

\section{METHODOLOGICAL FRAMEWORK}

In approaching such a variety of individual experiences, a uniform methodological approach to create unity seemed to be quite necessary. Thus, when I was in the field, I attempted to create a connecting thread utilizing the same methodology and tools in ex-

${ }^{2}$ Abhinaya, deriving from the Sanskrit root word $n i$ - meaning "to lead" -, can be defined as a mimetic portrayal of narrative themes through facial and bodily expression. Apart from this narrative and meaningful dance, Bharatanatyam pieces present also parts of Nritta, abstract dance (GASTON 1996: 257).

${ }^{3}$ Sнан 1998: 3.

4 'Rasa, literally meaning "taste" is the specific kind of aesthetic pleasure that penetrates the spectator when the dancer expresses the appropriate feeling' (NATALi 2009: 96).

${ }^{5}$ HanNa 1988: 102.

${ }^{6}$ BlackWood - Wieringa 1999: 17. 
changing with each of my collaborators. A constant process of participant observation, which I consider in this instance not as an ethnographic tool but as a practice of sharing which informed the whole fieldwork experience, allowed me to contextualize individual agency ${ }^{7}$ in the complexity of socio-cultural dynamics. At the same time, a particular combination of video recording and interview techniques gave me the opportunity to get closer to individual experiences in relation to specific dance pieces. During the informal dialogical exchanges I had with my collaborators, I used to ask them to describe movements and meanings of Abhinaya pieces which they consider as particularly close to their experiences, recording afterwards their performances of those same pieces. This methodology, which could be considered as an alternative modality to conduct Self-Confrontation interviews ${ }^{8}$, allowed me not only to understand the codified meanings of gestures and attitudes the dancers were using in impersonating characters through Abhinaya, but also to get close to the personal meanings they give to those pieces. Indeed, as anthropologist Deidre Sklar states, 'the ethnographer wants to know nothing less than how a given group of people find or, more accurately, make meaning. ${ }^{9}$ Combining observation and video recording with dancers' own explanations, I had the possibility to 'go beyond the visual surface' ${ }^{10}$, beyond the form, getting close to their living experiences.

In this essay I begin the exploration of what was co-produced through this methodological framework, a process that will be continued with the writing up of my Masters Dissertation. In particular, I will introduce the reader to the different cultural contexts in which my collaborators contextualise themselves: the field of LGBT (Lesbian, Gay, Bisexual, Transgender) activism of Chennai and the social group known in Southern India as Aravanis (transgender male to female). Within this general background, I will focus on the individual experiences of two dancers, one from each context, in relation to specific Abhinaya pieces they shared with me. Basing on my fieldwork experience, I will tell different individual stories, contextualizing them on the complexity of dynamics characterizing the Indian cultural system.

\footnotetext{
7 'In opposition to several social and anthropological perspectives considering human beings as completely conditioned by the cultural schemes of their society, in the 70 s the anthropological theory of agency emerged. The studies realized before this theory, mostly proposed what we could define as "cultural determinism", according to which the individuals are nothing more than finite products of their culture, unable to modify social schemes and actively build themselves. The theory of agency introduced a more elastic and dynamic perspective in light of which human beings have an active role in the construction of their culture: they are, indeed, "social actors", (NATALI 2009: 25).

${ }^{8}$ The term "Self-Confrontation" defines several kinds of interview techniques based on the replacement of the agent in the living situation which is the object of the interview through external artifacts as video films (BAKKA - GORE 2007: 2). In dance research this technique is usually based on the use by the researcher in the interview process of an already existent video of the social actor dancing. My research material was produced by inverting the two components of the technique: the video was recorded after the interview about the dance piece.

${ }^{9}$ SKlar 1991: 6.

${ }^{10}$ Felfoldi 2002: 18.
} 


\section{QUEERING BHARATANATYAM}

Feminist scholar Judith Butler considers gender as a cultural performance which 'grounds on the stylized repetition of acts through time', ${ }^{11}$ a repetition that gradually turns in norm. For some of my collaborators, the possibility to fail this repetition in dance, showing unconsidered possibilities that go beyond normative systems could have the power to 'destabilize received and rehearsed categories'. ${ }^{22}$ Part of my ethnographic experience took place within the context of LGBT (Lesbian, Gay, Bisexual, Transgender) activism in Chennai, with a number of homosexual and bisexual dancers who regularly involve dance in their activism. They define themselves and what they do as "queer"13, understanding the term as 'whatever is at odds with the normal, the legitimate, the dominant [...] as an horizon of possibilities whose precise extent and heterogeneous scope cannot in principle be defined in advance'14. Queering their Bharatanatyam they can share with people this horizon of unconsidered possibilities.

For the purposes of this paper, I will focus on one particular way of queering, exploring the individual experience of my collaborator Aniruddhan, professional Bharatanatyam dancer, queer activist and anthropologist. During our exchange in the field, he told me about several performances in which he crossed gender fixities to 'make people think and react, to make them feel uncomfortable or to make them say "finally someone did it!"" 15 . He considers the possibility of making people question established cultural schemes as an essential opportunity to criticise the problematic situation of LGBT social rights in Tamil Nadu, where homosexuality is currently considered to be a crime punishable by law ${ }^{16}$. Moreover, the act of "queering Bharatanatym" can be at the same time a mean to subvert the rigid heteronormativity characterizing this dance style itself. Indeed, as scholar and performer Hari Krishnan points out, 'in the early $20^{\text {th }}$ century, when sadir Kacheri was reinvented as Bharatanatyam, gender was re-imagined under colonial and upper caste nationalist frameworks that invented the male dancer as a hypermasculine, spiritual and patriotic icon for the emergent new nation ${ }^{17}$. Thus, within the context of professional Bharatanatyam in Chennai, male dancers usually do not perform female roles,

${ }^{11}$ Butler 1988: 520.

${ }^{12}$ Fraleigh 2004: 15.

13 “ 'Queer', a term that was once as much a slang for 'homosexual' as a word with homophobic acceptation, has successively become an open and elastic umbrella term which could define every conceptualization in terms of gender and sexuality which is not included in the normative dichotomy man-male, woman-female" (Prosser 1997: 309). In academic context, the term defines a post-structuralist theory that emerged in the early 1990s out of the field of Gay and Lesbian studies and proposes an understanding of sexuality and gender which emphasizes shifting boundaries, ambivalences and approaches gender identity as 'multiple, unstable and fluid social construction' (YeP 2004: 30).

${ }^{14}$ Halperin 1995: 62, cited in Dave 2012: 21.

${ }^{15}$ Interview with Aniruddhan, Bharatanatyam male dancer (25/07/2013).

${ }^{16}$ In 2009 the Delhi High Court overturned section 377 of the Indian Penal Code, a set of laws drafted in 1860 by British colonialists that makes gay sexual relationship punishable by up to life imprisonment. This governmental act was unfortunately revoked in December 2014, date since which homosexuality is back to be considered as a social crime.

${ }^{17}$ KRISHNAN 2009: 378. 
especially in Shringara (love-erotic) Abhinaya pieces which require a particularly erotic expression of love ${ }^{18}$ addressed to a male subject. Thus, they generally feel more comfortable in performing devotional pieces.

When I asked Aniruddhan to describe the piece that he feels as the most meaningful among those he performed in activist context, he told me about a Shringara Abhinaya piece part of a Varnam $^{19}$ telling the traditional story of the heroine (nayika) struggling for her lover and finding support in the female character of the sakhi, her best friend. He told me that it was really important for him to perform a piece which is usually performed only by female dancers but is actually quite close to his own reality. 'Every gay man has got his best female friend,' he said, 'the one he goes to ask for advice when there are problems with his boyfriend, so how is this different? Here there is this woman who is asking a female friend to be a mediator, it is extremely relatable to the contemporary gay context.'20

As I could afterword observe in the video of this piece, ${ }^{21}$ he was attempting to create ambiguity, openness in relation to the gender of the character he was enacting. 'I did not specify anything about my performance, I wanted to show that I could have been a man who moves and feels like a woman or a man who has feelings for another man and it would have not really changed the fact that I was suffering for love. ${ }^{22}$ By leaving the boundaries unfixed, open, he was attempting to show that what seems to be a naturally right norm could actually be a culturally contestable construct. This was his way to queer the form, his way to queer Bharatanatyam, crossing gender boundaries and leaving them open in order to share with people the idea that 'a body written by culture, can always be re-scribed'23.

\section{RE-INVENTING WORLDS THROUGH ABHINAYA}

What Bharatanatyam can be for a dancer involved in the queer activist context of Chennai, is in many ways different and far from what it can be for those subjects known in Tamil Nadu as Aravanis ${ }^{24}$ (and as Hijra in other parts of India). These social actors are men who identify themselves as female and usually change their sex from male to female during their first teen years. Their social group has occupied a specific place in Indian

${ }^{18}$ We could generally distinguish between two different types of Abhinaya pieces: the shringara (erotic love) pieces, usually telling the struggling of a nayika (heroin) for her lover and the bhakti (devotional) pieces, in which love is usually expressed in a less erotic modality.

${ }^{19}$ A Varnam is a complex choreutic composition including both Abhinaya and "non-thematic dance".

${ }^{20}$ Interview with Aniruddhan, Bharatanatyam male dancer (25/07/2013).

${ }^{21}$ In this case, instead of recording the dancer performing the piece that was object of the interview, it was the dancer itself who gave me the video of the dance program during which he performed that piece in Chennai.

${ }^{22}$ Interview with Aniruddhan, Bharatanatyam male dancer (25/07/2013).

${ }^{23}$ Interview with Aniruddhan, Bharatanatyam male dancer (25/07/2013).

${ }^{24}$ The term refers to a section of the popular epic poem Mahabharata. As Priya Babu points out, 'Aravanis see themselves as the transgendered aspect that Krishna assumed for a night to marry Aravan, to fulfil his wish for conjugal union before his sacrifice to the gods the next morning' (PRIYA 2007: 17, cited in GovINDAN - VASUdeVAn 2008: 9). 
society for a long period of time: traditionally considered as bearers of good luck, they used to have an important role in several kinds of ritual, where their main functions were related to dance. ${ }^{25}$ Although the general belief about Aravanis is somehow still strong in Indian society, today they are placed mainly out of the cast system ${ }^{26}$ and, in order to earn a living, they are obliged to engage in a variety of jobs, often including prostitution. What the opportunity of learning Bharatanatyam as a high level, "traditional", "devotional" dance style ${ }^{27}$ could be for them, in the rare case they have the chance to access it, is a real, concrete change in their social position and therefore in their life. Focusing on the experience of one of my collaborators, Narthaki, we will explore how Bharatanatyam can become for these social actors a space to define and confirm who they are, re-inventing the world around them.

Narthaki was born and grew up in Madurai (Tamil Nadu), a place where she experienced the troubles of being different and having no real place for herself in the society. Her lucky access to a fifteen-year Bharatanatyam training with the well-known guru Kitappa Pillai in Tanjore allowed her to become what she is today: part of the high-level Bharatanatyam culture in Chennai. Strangely enough for an Aravani, she is currently considered as one of the best Bharatanatyam exponents in the city, with the chance of teaching and performing also abroad. During our exchanges, she explained how Bharatanatyam changed her life not only giving her a concrete space in society as a professional dancer, but also helping her to explore, define and confirm 'who she is and what is her place in the world' 28 . Through dance she understood that her place is spirituality, that she was born to worship and love god through dance.

What she described as the most important and meaningful piece to her is a Varnam that, she said, tells her story. The piece is about a woman who is rejected by society, who is unable to find a love relationship, who is destined to give herself to god, the only one who can love her: Amba, a character of the popular epic poem "Mahabharata". When Narthaki performs this piece she feels like she is talking about herself. 'It is my story,' she said, 'a story of rejection by society and loneliness'. ${ }^{29}$ Like Amba, refused by several men and obliged to find love only in devotion, Narthaki sees her dance as a way to reach God. One day she performed for me part of the piece allowing me to record it. In every single gesture she performs in that video, it is possible to feel that she is telling her own story, reconfirming who she is, a woman who found her place in the spiritual milieu, in the expression

${ }^{25}$ NANDA 1999: 9.

${ }^{26}$ What is commonly known as "caste system" is a strict system of social stratification, which defines Indian communities in endogamous hereditary groups called Jati. Considered as part of the Hindu system to classify the universe, this system determines the socio-economic positions of the members born in each of the groups. Although it undergone a multitude of interpretations and transformations over the course of Indian history, the system is still today an essential element of social organization in India (BELKIN 2008: 1).

${ }^{27}$ The so-called revival, a process made by exponents of the brahamin caste, the higher level of the caste system, established Bharatanatyam as a prestigious all-India and an international classical art. Since then, this style is considered to be the high level dance of India and is therefore mainly practiced by the upper classes (Allen 1997: 65). Thus, the possibility that an Aravani, placed at the bottom of the caste system, could have to access this practice are quite scarce.

${ }^{28}$ Interview with Narthaki (22/08/2013).

${ }^{29}$ Interview with Narthaki (22/08/2013). 
through dance of devotional love. Abhinaya, for her, is a space to continuously confirm her feminine identity, as well as her role of spiritual mediator through choreutic art. In "tradition", she found her own place as a transgender in Indian society, in "tradition" she found a space to re-invent her own world.

\section{CONCLUSION}

This exploration could be considered as the beginning of a confrontation with my fieldwork experience, as part of a long process of re-working and re-consideration. My attempt in this paper was to introduce the reader to the complexity of the cultural dynamics I explored in the field, as well as to the variety and multiplicity of experiences I shared with my collaborators. As an anthropologist, what I am interested in exploring and sharing, is the meaning these social actors give to their acting, to their dancing. Emphasizing the difference, the peculiarity and at the same time the similarity, my research is an attempt to explore what Dance Anthropology is mainly about, the place dance could occupy in people's life. ${ }^{30}$ The personal stories told in this paper clearly define the general theoretical and methodological framework on which this exploration is based: different social actors expressing their ways of "being queer" through the same narrative means of Abhinaya; individual stories, individual meanings faced and told with the same ethnographic approach.

\section{LITERATURE}

AlLen, Matthew Harp

1997: Rewriting the Script for South Indian Dance. TDR (The Drama Review) Journal of Performance Studies 41(3), 63-100.

BAKKA, Egil - Gore, Georgiana

2007: Constructing Dance Knowledge in the Field: Bridging the Gap between Realisation and Concept. In: Proceedings of Re-thinking Practice and Theory. International Symposium on Dance Research. Paris: Society of Dance History Scholars, 93-97.

BeLKIN, Erica

2008: Creating Groups Outside the Cast System: The Devadasis and Hijra of India. Honors Theses - All, Middletown: Wesleyan University.

BlackWood, Evelyn - Wieringa, Saskia

1999: Female Desire: Same-Sex Relations and Transgender Practices through Cultures. New York: Columbia University Press.

Butler, Judith

1988: Performative Acts and Gender Constitution: An Essay in Phenomenology and Feminist Theory. Theatre Journal 40(4), 519-530.

DAVE, Naisargi

2012: Queer Activism in India: A Story in the Anthropology of Ethics. Durham and London: Duke University Press.

${ }^{30}$ KuRATH 1960: 250. 
FELFÖLDI, L.

2002: Dance Knowledge. To Cognitive Approach in Folk Dance Research. In: FISKviK, Anne Margrete BAкKa, Egil (eds.): Dance Knowledge - Dansekunnskap. International Conference on Cognitive Aspects of Dance. Proceedings Sixth NOFOD Conference, Trondheim, January 10-13, 2002, 1-20.

Fraleigh, Sondra Horton

2004: Dancing Identity: Metaphysics in Motion. Pittsburgh: University of Pittsburgh Press.

Gaston, Anne-Marie

1996: BharataNatyam: From Temple to Theatre. New Delhi: Manohar.

Govindan, Padma - Vasudevan, Aniruddhan

2008: The Razor's Edge of Oppositionality: Exploring the Politics of Right-Based Activism by Transgender Women in Tamil Nadu. Online source available at: http://www.lassnet.org/2009/readings/govindanvasudevan2008razors-edge.pdf

HALPERIN, David M.

1995: Sain Foucault: Towards a Gay Hagiography. New York: Oxford University Press.

Hanna, Judith Lynne

1988: Dance, Sex and Gender: Signs of Identity, Dominance, Defiance, and Desire. Chicago: University of Chicago Press.

KriSHNAN, Hari

2009: From Gynemimesis to Hypermasculinity: The Shifting Orientation of Male Performers of South India Court Dance. In: Fisher, Jennifer - ShAY, Anthony (eds.): When Men Dance: Choreographing Masculinity across Borders. New York: Oxford University Press.

Kurath, Gertrude Prokosch

1960: Panorama of Dance Ethnology. Current Anthropology 1(3), 233-254.

NANDA, Serena

1999: Neither Man or Woman: The Hijras of India. Belmont, CA: Wadsworth Publishing.

Natali, Cristina

2009: Percorsi di Antropologia della Danza. Cortina Libreria Milano.

O'SheA, Janet M.

2007: At Home in the World: Bharata Natyam on the Global Stage. Middletown, CT: Wesleyan University Press.

PRIYA, Babu

2007: Aravanigalsamugyavaraiviyal. Chennai: Thentisai.

Prosser, Jay

1997: Transgender. In: Medhurst, Andy - Munt, Sally (eds.): Lesbian and Gay Studies: A Critical Introduction. London: Cassell, 309-326.

Shah, Purnima

1998: Transcending Gender in the Performance of Kathak. Dance Research Journal 30(2), 2-17.

SKLAR, Deidre

1991: On Dance Ethnography. Dance Research Journal 23(1), 6-10.

YEP, A. Gust

2004: The Violence of Heteronormativity in Communication Studies: Notes on Injury, Healing and Queer World-Making. In: Yep, A. Gust - LovaAs, E. Karen - Elia, P. Elia (eds.): Queer Theory and Communication: From Disciplining Queers to Queering the Disciplines. Binghamton (NY): Harrington Park Press. 